\title{
Effect of FOLFOX on minimal residual disease in Stage III colon cancer and risk of relapse
}

\author{
Nigel P Murray ${ }^{1,2}$, Sócrates Aedo², Ricardo Villalon ${ }^{4}$, Marco Antonio López $^{5}$, Simona Minzer ${ }^{5}$, Lorena Muñoz ${ }^{5}$, Shenda Orrego ${ }^{5}$, Luis Contreras $^{5}$, \\ Lucas Arzeno 5 and Eghon Guzman ${ }^{5}$
}

\begin{abstract}
${ }^{1}$ Servicio de Medicina, Hospital de Carabineros de Chile, Simón Bolívar 2200, Ñuñoa, Santiago 7770199, Chile
${ }^{2}$ CTC Unit, Faculty of Medicine, University Finis Terrae, Providencia, Santiago 7501015, Chile

${ }^{3}$ Faculty of Medicine, University Finis Terrae, Providencia, Santiago 7501015, Chile

${ }^{4}$ Servicio de Coloproctologia, Hospital de Carabineros, Simón Bolívar 2200, Ñuñoa, Santiago 7770199, Chile

${ }^{5}$ Faculty of Medicine, University Mayor, San Pio X 2422, Providencia, Santiago 7500041, Chile
\end{abstract}

\begin{abstract}
Introduction: $25 \%$ of Stage III colon cancer patients relapse within 5 years due to minimal residual disease (MRD) not eliminated by surgery and chemotherapy. We hypothesise that sub-types of MRD, defined by circulating tumour cells (CTCS) and bone marrow micro-metastasis $(\mathrm{mM})$ have different types and kinetics of relapse.
\end{abstract}

Patients and Methods: One month of curative surgery and 1 month after completing six cycles of FOLFOX chemotherapy blood and bone marrow samples were taken to detect CTCs and $\mathrm{mM}$ using immunocytochemistry with anti-carcino-embryonic antigen (CEA). Follow up was up to 5 years or disease progression defined as new images on CT scanning. Survival curves using Kaplan-Meier (KM) and Restricted Mean Survival Time (RMST) were calculated for three prognostic groups: CTC and mM negative, CTC negative $\mathrm{mM}$ positive, and CTC positive.

Results: 76 patients (39 men) participated, mean age 67 years, median follow-up 3.6 years. The response to chemotherapy was heterogeneous and MRD pre-treatment did not predict response to therapy. Of 21 patients MRD (-), 20 remained MRD negative and one patient became $\mathrm{mM}(+)$; of 21 patients $\mathrm{mM}(+), 10$ became MRD (-), 8 remained the same and 3 became CTC (+); of the 34 CTC positive, 8 became MRD (-), 8 with only mM, and 18 remained positive.

After chemotherapy, 38 patients were negative for CTC and mM, 17 were positive for only $\mathrm{mM}$, and 21 for CTCs. For the whole cohort, the 5 year KM was $58 \%$, the median survival was not reached. For the three prognostic groups, the KM 5-year survivals were $87 \%, 58 \%$, and $4 \%$, respectively, the median survival for patients MRD negative and $\mathrm{mM}$ only was not reached. RMST for the whole cohort was 3.6 years, for the three prognostic groups the RMST was 4.6 years, 4.0 years, and 1.5 years, respectively. Serum CEA was significantly higher pre-surgery in the CTC positive group. There were no significant differences with respect to age or sex between the three groups.

Conclusions: MRD subtypes pre-chemotherapy did not predict treatment response. Post-chemotherapy MRD subtypes were associated with the pattern of failure and time
Correspondence to: Nigel P Murray Email: nigelpetermurray@gmail.com

ecancer $2019,13: 935$

https://doi.org/10.3332/ecancer.2019.935

Published: $27 / 06 / 2019$

Received: 13/02/2019

Publication costs for this article were supported by ecancer (UK Charity number 1176307).

Copyright: ( $)$ the authors; licensee ecancermedicalscience. This is an Open Access article distributed under the terms of the Creative Commons Attribution License (http:// creativecommons.org/licenses/by/3.0), which permits unrestricted use, distribution, and reproduction in any medium, provided the original work is properly cited. 
to failure. MRD negative patients had an excellent prognosis with $87 \%$ disease-free survival at 5 years. Those with only mM had a similar outcome up to 2 years and then were at increasing risk of late failure. Patients who were CTC positive had a high risk of early failure. MRD subclassification may be useful to define the risk of relapse in Stage III colon cancer patients and warrants further studies with a larger number of patients.

Keywords: colon cancer, circulating tumour cells, micro-metastasis, minimal residual disease, prognosis

\section{Introduction}

Following surgery for Stage III colon cancer, the NCCN guidelines (2008) [1] recommend the use of adjuvant chemotherapy. This is because up to $30 \%$ of patients with Stage III colon cancer will develop disease recurrence within 5 years of surgery [2]. At the time of diagnosis and surgical resection, these patients had no signs of distant metastasis and as such, disease recurrence is a result of occult tumour dissemination prior to treatment. These disseminated tumour cells that remain after curative surgery are termed minimal residual disease (MRD). Circulating tumour cells (CTCs) detected after curative surgery are associated with decreased disease-free survival and overall survival [3].

Although bony metastases are infrequent in patients with colon cancer, the presence of disseminated tumour cells in bone marrow samples has been reported to be of the order of $30 \%$ and is associated with a worse prognosis [4]. These undetected micro-metastatic tumour cells are responsible for disease relapse, thus the detection of these cells in easily accessible tissues, such as blood and/or bone marrow, may be important to identify patients at risk of treatment failure and who could benefit from other therapeutic strategies [3].

We hypothesise that there are at least two sub-types of MRD, that those patients with CTCs have a worse prognosis and shorter times to treatment failure, while those with only bone marrow micro-metastasis are at risk of late failure. Tumour cells that are not actively proliferating are relatively resistant to chemotherapy; in addition, they may have phenotypic characteristics that confer resistance to anti-proliferative agents. Many tumour cells found in the bone marrow have been reported to quiescent and are not eradicated even with high-dose chemotherapy [5].

We present a prospective observational study of the effect of six cycles of FOLFOX chemotherapy on MRD in Stage III colon cancer patients and the association with time to relapse and progression-free survival.

\section{Patients and methods}

A prospective single-institution study of consecutive patients who complied with the following criteria: newly diagnosed non-metastatic colon cancer, absence of previous colon cancer, or inflammatory colon disease and absence of metastasis seen on CT scan imaging of thorax, abdomen, and pelvis.

For each patient, after giving informed written consent, the following were recorded: a) sex, b) age, c) date of surgical treatment, and d) depth of primary tumour invasion $(\mathrm{T})$ and nodal infiltration $(\mathrm{N})$ according to the American Joint Committee on Cancer (AJCC) tumour/node/ metastasis (TNM) classification and staging system for colon cancer [6]. Serum levels of carcino-embryonic antigen (CEA) were taken the week before surgery and measured using the Cobas e601 analytical system (Roche Diagnostics, USA). A serum level of $<3.0 \mathrm{ng} / \mathrm{ml}$ venous blood was considered to be normal. Patients classified as Stage III were included in the study.

\section{CTC detection}

Blood samples were collected 1 month after curative surgery, defined as a surgical bed free of any gross residual tumour and surgical resection margins pathologically negative for tumour invasion, and 1 month after completing six cycles of FOLFOX chemotherapy. 
Venous blood was collected using a $21 \mathrm{G}$ butterfly needle, the first $5 \mathrm{ml}$ was discarded to prevent possible contamination by epithelial cells and the second $8 \mathrm{ml}$ was collected into tubes containing ethylenediaminotetraacetic acid (EDTA, BD-Vacutainer $\left.{ }^{\circledR}\right)$. The samples were transported at room temperature and processed within 24 hours.

Mononuclear cells were obtained using differential gel centrifugation with Histopaque 1.077® (Sigma-Aldrich, USA) according to the manufacturer's instructions. The obtained cells were re-suspended in $100 \mu \mathrm{l}$ of autologous plasma and $25 \mu \mathrm{l}$ aliquots of cell suspension used to prepare four slides (silanised, DAKO, USA), they were air dried for 24 hours and finally fixed using a solution of $70 \%$ ethanol, $5 \%$ formaldehyde, and 25\% phosphate buffered saline $\mathrm{pH} 7.4$ (PBS) for 5 minutes and washed twice with PBS.

The slides were processed within 1 hour of fixation and incubated with monoclonal anti-CEA clone 11-7 (DAKO-USA) for 1 hour at room temperature, CTCs were identified using an alkaline-phosphatase-anti-alkaline phosphatase based system (LSAB2, DAKO, USA) with neofuschin as the chromogen and levisamole as an endogenous alkaline phosphatase inhibitor. Positive samples underwent a second process using anti-CD45 clone 2B11 + PD7/26 (DAKO, USA), incubated for 1 hour at room temperature and identified using a peroxidase-based system (LSAB2, DAKO, USA) with DAB (3,3'diaminobenzadine tetrachloride) as the chromogen.

A CTC was defined according to the morphological criteria of ISHAGE [7], as a nucleated cell expressing CEA but not CD45. A positive test was defined as the detection of at least one cell/8 $\mathrm{ml}$ venous blood (Figure 1).

\section{Bone marrow micro-metastasis}

Although previous studies have used bone marrow aspirates to detect micro-metastasis, we used "touch preparations" from bone marrow biopsy specimens.

It has been reported that prostate tumour cells detected in bone marrow aspirates are phenotypically different from those prostate cells detected in bone marrow biopsies and may not represent "true" micro-metastasis but rather cells circulating in the bone marrow [8].

A bone marrow biopsy was taken from the posterior superior iliac crest 1 month after surgery and 1 month after completing chemotherapy. The samples were used to prepare four "touch preps" using silanised slides (DAKO, USA). The slides were processed in the same as for CTCs.

After completing chemotherapy, the patients were divided into three prognostic groups: patients negative for both CTCs and micro-metastasis, patients negative for CTCs and positive for micro-metastasis, and third those CTC positive with or without the presence of micro-metastasis (Figure 2).

Figure 1. Circulating tumour cell and leukocyte and the expression of CEA. CTC expressing CEA (red) and negative for membrane CD45. Leukocyte negative for CEA and positive for membrane CD45. 

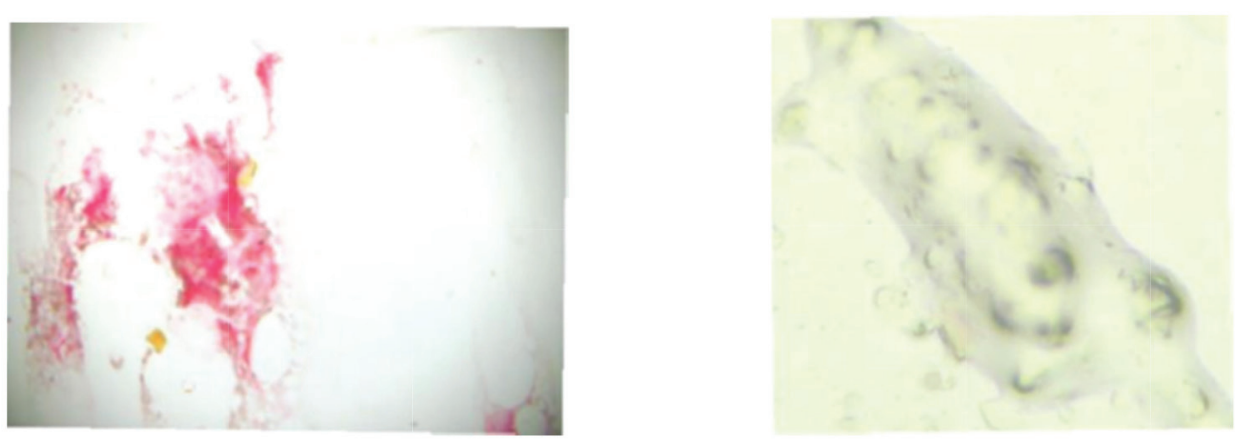

Figure 2. Bone marrow positive and negative for CEA expressing cells. Micro-metastasis CEA positive (red). Bone marrow negative for CEA.

\section{Study end point}

The primary study end point was the presence of metastasis detected on CT scan and the secondary end point the time from surgery to the detection of metastasis.

\section{Follow-up}

Patients underwent three monthly follow-ups for the first 2 years then six monthly until 5 years of follow-up were completed. Relapse was defined as a new lesion detected on CT scanning of thorax, abdomen, and pelvis. Patients were censured at the time of relapse or after 5 years of follow-up.

\section{Statistical analysis}

The analysis was performed using the program Stata (Stata/SE 15.0 for Windows ${ }^{\circledR}$, Copyright 1985-2017 StataCorp LLC) using descriptive statistics for measurements of central tendency (mean and median) and dispersion [standard deviation (SD) and inter-quartile range (IQR)]. Nominal dichotomous variables were described as proportions with their respective confidence intervals [9]. The three prognostic groups determined after chemotherapy were compared for differences in age, sex, and serum CEA pre-surgery. Pearson's Chi-squared was used to compare frequencies and the Kruskal-Wallis test to determine whether samples originated from the same distribution. A $p$-value of $<0.05$ was taken to signify statistical significance and all tests were two-tailed [9].

To evaluate the time to treatment failure, a non-parametric survival analysis was performed at three and 5 years of follow-up. The survival proportion and median survival for the three proportion prognostic groups were determined using the Kaplan-Meier model [9, 10]. The Restricted Mean Survival Time (RMST) for treatment failure was determined for 5 years of follow-up for the whole cohort and each prognostic group. The RMST establishes the expected time for an event to occur during a 5 year observation period and its value is the area under the Kaplan-Meier non-parametric survival curve [10]. The Log-Rank test was used to compare disease-free progression survival times for each prognostic group [10].

The analysis of disease-free progression survival did not fulfil the proportional risk criteria of the Cox regression model, and as such a flexible parametric survival model (FP) was used to predict the RMST and hazard ratios [11, 12]. According to the proposed hypothesis for the prediction of treatment failure, an FP model was built using the predictor variables of age, sex and prognostic group. The FP model is a regression method in which the dependent variable is the disease-free progression survival. The discrimination of the predictive model was determined using Harrell's C discrimination index [13]. 
Table 1. Clinical-pathological characteristics according to prognostic group.

\begin{tabular}{|c|c|c|c|c|}
\hline Characteristic & CTC $+\mathrm{mM}$ negative $N=38$ & CTC negative mM Positive $N=17$ & CTC positive $N=21$ & $p$ value two tail \\
\hline $\begin{array}{l}\text { Age (years) } \\
\text { Median; (IQR) }\end{array}$ & $66(16)$ & $68(15)$ & $68(19)$ & $0.62^{a}$ \\
\hline $\begin{array}{l}\text { Male sex } \\
N(\%)\end{array}$ & $17(44)$ & $8(47)$ & $14(67)$ & $0.25^{b}$ \\
\hline $\begin{array}{l}\text { Tumour differentiation } \\
\text { Well } \\
\text { Moderate } \\
\text { Poor } \\
\text { Lymphatic invasion } \\
\text { Vascular invasion } \\
\text { Peri-neural invasion }\end{array}$ & $\begin{array}{c}22 \\
12 \\
4 \\
8 \\
8 \\
2 \\
\end{array}$ & $\begin{array}{c}7 \\
8 \\
2 \\
4 \\
7 \\
18 \\
\end{array}$ & $\begin{array}{c}4 \\
8 \\
9 \\
13 \\
18 \\
3 \\
\end{array}$ & $\begin{array}{c}0.01^{\mathrm{b}} \\
0.004^{\mathrm{b}} \\
<0.001^{\mathrm{b}} \\
0.44^{\mathrm{b}}\end{array}$ \\
\hline $\begin{array}{l}\text { CEA } \\
\% \text { increased } \\
n(\%) \\
\text { median (IQR) } \mathrm{ng} / \mathrm{ml}\end{array}$ & $\begin{array}{c}16(42) \\
2.96(\text { IQR } 2.05-5.30)\end{array}$ & $\begin{array}{c}7(41) \\
3.05(\text { (IQR 2.22-8.03) }\end{array}$ & $\begin{array}{c}16(71) \\
7.83(\text { IQR 2.49-17.08) }\end{array}$ & $\begin{array}{c}0.03^{b} \\
\text { Gp A versus GpC 0.002 }\end{array}$ \\
\hline
\end{tabular}

$\mathrm{IQR}=$ inter quartile range; $\mathrm{CTC}=$ circulating tumour cell; $\mathrm{mM}=$ micro-metastasis.

aKrusal-Wallis Test.

${ }^{\mathrm{b}} \mathrm{Chi}$ squared.

Of the CTC group, only $1 / 21$ (5\%) patient was negative for micro-metastasis.

\section{Ethical considerations}

The study was approved by the local ethics committee and fully complied with the Declaration of Helsinki.

\section{Results}

The observed cohort included 76 patients, 39 (51\%) males with a median age of 67 years (IQR 16 years) and a median follow up time of 3.6 years (range $0.25-5.0$ years). Patients negative for both CTC and micro-metastasis had a significantly higher frequency of well-differentiated tumours and significantly lower frequency of lymphatic and vascular invasion in the primary tumour. There were no significant differences with respect to age, sex or peri-neural invasion. Overall, 42/76 (55\%) of patients had an increased serum CEA; the frequency of an abnormal level increased from patients negative for both CTC and micro-metastasis to patients CTC positive ( $p=0.03$ ). With respect to the median serum CEA level, the only significant difference was between patients negative for both CTC and micro-metastasis and patients CTC positive (Table 1).

\section{Effect of chemotherapy on minimal residual disease}

Prior to chemotherapy, 21 (28\%) patients were negative for both CTC and micro-metastasis, 21 (28\%) positive for micro-metastasis and negative for CTCs, and 34 (44\%) were CTC positive. The response to chemotherapy was heterogeneous and the type of minimal residual disease pre-chemotherapy did not predict the response (Table 2). 
Table 2. Minimal residual disease pre-chemotherapy and post-chemotherapy.

\begin{tabular}{|c|c|}
\hline Pre-chemotherapy & Post-chemotherapy \\
\hline \multirow[t]{3}{*}{ CTC and $\mathrm{mM}(-) \mathrm{N}=21$} & CTC and $\mathrm{mM}(-) \mathrm{N}=20$ \\
\hline & CTC $(-)$ and $m M(+) N=1$ \\
\hline & $\mathrm{CTC}(+) \mathrm{N}=0$ \\
\hline \multirow[t]{3}{*}{ CTC $(-)$ and $\mathrm{mM}(+) \mathrm{N}=21$} & CTC and $m M(-) N=10$ \\
\hline & CTC $(-)$ and $m M(+) N=8$ \\
\hline & $\operatorname{CTC}(+) N=3$ \\
\hline \multirow[t]{3}{*}{$\operatorname{CTC}(+) N=34$} & CTC and $m M(-) N=8$ \\
\hline & $\mathrm{CTC}(-)$ and $\mathrm{mM}(+) \mathrm{N}=8$ \\
\hline & CTC $(+) N=18$ \\
\hline
\end{tabular}

Table 3. Comparing observed survival (Kaplan Meier) versus predicted survival (Model FP) for treatment failure at 3 and 5 years.

\begin{tabular}{|l|c|c|c|c|}
\hline & $\begin{array}{c}\text { \% Observed survival } \\
3 \text { years }(95 \% \mathrm{Cl})\end{array}$ & $\begin{array}{c}\text { \% Predicted survival } \\
\mathbf{3} \text { years }\end{array}$ & $\begin{array}{c}\text { \% Observed survival } \\
5 \text { years }(95 \% \mathrm{Cl})\end{array}$ & $\begin{array}{c}\text { \% Predicted survival } \\
5 \text { years }\end{array}$ \\
\hline CTC and mM negative & $92 \%(77 \%-97 \%)$ & $92 \%$ & $87 \%(67 \%-95 \%)$ & $88 \%$ \\
\hline $\begin{array}{l}\text { CTC negative mM } \\
\text { positive }\end{array}$ & $71 \%(43 \%-87 \%)$ & $74 \%$ & $58 \%(32 \%-76 \%)$ & $62 \%$ \\
\hline CTC positive & $6 \%(0.5 \%-24 \%)$ & $11 \%$ & $6 \%(0.5 \%-24 \%)$ & $4 \%$ \\
\hline
\end{tabular}

CTC = circulating tumour cell; $\mathrm{mM}=$ micro-metastasis

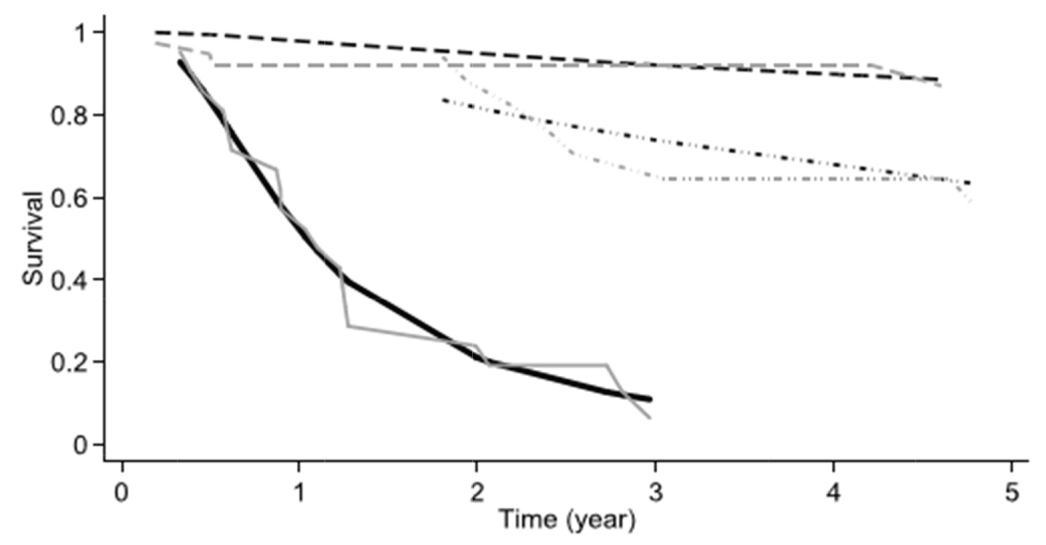

\begin{tabular}{|c|c|}
\hline Observed survival & Predicted survival \\
\hline $\begin{array}{l}---- \text { CTC and } \mathrm{mM} \text { negative } \\
\ldots \ldots-\text { CTC negative, mM positive }\end{array}$ & $\begin{array}{l}--- \text { CTC and } \mathrm{mM} \text { negative } \\
\ldots \ldots \ldots \text { CTC negative and } \mathrm{mM} \text { positive }\end{array}$ \\
\hline - CTC positive & CTC positive \\
\hline
\end{tabular}

Figure 3. Comparing the observed survival (Kaplan-Meier) and predicted survival (flexible parameter model) at 5 years according to prognostic group. 
Table 4. RMST at 5 years for treatment failure according to prognostic group.

\begin{tabular}{|l|c|c|}
\hline & RMST Kaplan-Meier years $(95 \% \mathrm{Cl})$ & RMST FP model \\
\hline CTC and $\mathrm{mM}$ negative $\mathrm{N}=38$ & 4.6 years $(4.2-5.0$ years) & 4.7 years \\
\hline CTC negative and $\mathrm{mM}$ positive $\mathrm{N}=17$ & 4.0 years $(3.4-4.7$ years) & 4.0 years \\
\hline CTC positive & 1.5 years (1.0-2.0 years) & 1.4 years \\
\hline
\end{tabular}

$\mathrm{CTC}=$ circulating tumour cells; $\mathrm{mM}=$ micrometastasis, $\mathrm{RMST}=$ restricted mean survival time; $\mathrm{FP}=$ flexible parameter.

\section{Minimal residual disease after chemotherapy and patient outcome}

38 patients (50\%) were both CTC and micro-metastasis negative, 17 (22\%) patients were only positive for micro-metastasis, and finally, 21 (28\%) were CTC positive. 31 (41\%) patients relapsed within the 5-year study period. After 3- and 5 years of follow up, the Kaplan-Meier survival for relapse-free survival was, respectively, 64\% (95\% Cl 52\%-74\%) and 58\% (95\% Cl 46\%-69\%), the median relapse-free survival was not reached. For each prognostic group, the three and five relapse-free survivals are shown in Table 3. Individuals negative for both CTCs and micro-metastasis and those with only micro-metastasis did not reach the median relapse-free survival. Differing those patients with CTCs showed a median relapse-free survival of 1.1 years ( $95 \% \mathrm{Cl} 0.6-1.28$ years). Figure 3 shows the results as a graph.

The RMST for treatment failure for the whole cohort was 3.6 years ( $95 \% \mathrm{Cl} 3.2-4.0$ years). Table 4 shows the RMST at 5 years for each prognostic group, from the observed Kaplan-Meier and Predicted (FP model) survival models. The Log-rank test showed a significant difference between groups $(p<0.01)$. There was no significant difference for sex or age of the patient $(p=0.99)$. The calculated hazard ratios (baseline CTC and micro-metastasis negative) were for CTC negative micro-metastasis positive HR $1.30(p=0.02)$ and CTC positive 3.35 ( $p>0.01$ ). The observed survival (Kaplan-Meier) was concordant to the survival predicted by the flexible parameter model, Harrell's $\mathrm{C}$ was 0.82 classified as good.

\section{Discussion}

In Stage III colon cancer treated with curative surgery and adjuvant FOLFOX chemotherapy, the relapse rate is reported to be approximately $30 \%$. In this small study, a group of 76 patients $40 \%$ relapsed within the 5 -year study period. The inference is that undetected minimal residual disease not eliminated by chemotherapy was present and was responsible for the relapse of the patient.

Although all of the patients were classified as Stage II, the individual behaviour of cancer is heterogeneous with differing responses to the same chemotherapy regime, which in turn leads to variable outcomes.

In the study, we used a Histopaque ${ }^{\circledR}$ differential centrifugation method to enrich CTCs from whole blood and then standard immunocytochemistry to detect CTCs. Detection of CTCs is method dependent, CTCs are a rare event being present in very low concentrations in the blood and all of the detection methods have an enrichment method. The only FDA approved system, CellSearch ${ }^{\circledR}$ is an EpCAM based method, although EpCAM is a conventional marker expressed by cancer cells of epithelial origin it is not expressed by all CTCs. CTCs which have undergone the epithelial-mesenchymal-transition have decreased expression of epithelial markers, such as EpCAM and cytokeratins [14], and will not be detected. EpCAM positive cells have been detected in patients with benign inflammatory disease and adenomatous polyps [15] leading to false-positive results. Whether intestinal mucositis post-chemotherapy is associated with circulating epithelial cells is an unknown parameter. As such EpCAM cannot be considered as a universal marker for CTC detection.

Non-specific enrichment methods rely on cell size, cell density, and deformability. Density gradient centrifugation is a conventional approach for separating blood components on the basis of differing sedimentation coefficients, with a reported recovery rate of spiked cells of $80 \%-$ $87 \%$ [16]. Although inexpensive and reliable the disadvantages include the loss of large CTCs and cell clusters and the low purity due to the presence of leukocytes. Membrane microfilters have been developed which allow the rapid processing of large blood volumes but again have 
the same disadvantages as differential centrifugation. The use of microfluidics permits excellent purity with high capture rates but requires pre-processing to reduce the volume of the sample. The use of non-EpCAM-based approaches for CTC enrichment has been reviewed by Tellez et al [17]. After enrichment we used anti-CEA immunocytochemistry to identify CTCs, we acknowledge that immunocytochemistry is less sensitive by a factor of 10-100 fold than RT-PCR but can be implemented in the routine laboratory of a general hospital. We suggest that the sensitivity may not be an important factor; the question is the clinical utility. As yet, independent of the method to detect CTCs, no cut-off for a lower limit of detection has been established to determine clinical utility. The importance of this observation is the following; it may not be necessary to eliminate all CTCs to obtain a clinically important effect. This has been seen in haematological malignancies, patients transplanted for chronic myeloid leukaemia may have been in remission clinically and according to standard haematological parameters for years, yet analysis using RT-PCR demonstrates the presence of very low numbers of leukemic cells in the bone marrow and the patients had remained relapse free for more than ten years $[18,19]$. In the study presented, there was a clinically useful association in that patients with a high risk of early relapse were identified. Thus, the lower sensitivity of Ficoll gel density gradient may be sufficient to detect CTCs at levels that are clinically significant, but it was beyond the scope of this study to answer this question.

More recently the use of circulating free DNA has been used as a prognostic marker. In colon cancer-specific DNA mutations have been identified, BRAF, K-ras, N-ras, and PIK3CA mutations. Circulating DNA is found in all people, as a result of necrosis, apoptosis, or secretion. Of this total circulating free DNA, a small percentage of free DNA can be identified in patients with cancer when there are specific mutations which separate 'normal' DNA from tumour 'DNA'. The presence of circulating free tumour DNA for the mutations BRAF, K-ras, N-ras, and PIK3CA mutations has been used to identify patients with MRD and also as a marker for the resistance to EGFR therapy, such as cetuximab or panitumumab [20]. The use of CTC single cell DNA analysis compared with ctDNA detection showed a concordance of $97 \%$ but there was considerable heterogeneity of EFGR expression and genetic alterations in K-ras and PIK3CA [20]. This heterogeneity is seen both intra- and inter-patient, may explain the variable response rates to anti-EGFR therapy [21] and may change with time as a result of treatment, these differences are seen earlier in CTC single cell DNA analysis than ctDNA [22].

The CTC positive group was not divided into those micro-metastasis positive and negative, theoretically patients con be CTC positive and bone-marrow micro-metastasis negative, CTC dissemination occurring from a non-bone marrow micro-metastasis. This has been reported in other cancers, such as prostate [23] and breast [24]; however, in this reported study, only one patient was CTC positive and bone marrow micro-metastasis negative. In prostate and breast cancer studies, it has been reported that CTC positivity is associated with early failure independent of bone marrow micro-metastasis $[23,24]$. In the clinical and for the single patient, all CTC positive patients were included as a single group.

The results of the study suggest that the presence of minimal residual disease after chemotherapy has clinically important consequences. The three sub-types of MRD pre-chemotherapy did not predict the results of treatment. Overall, 30 (39.9\%) of patients had a different sub-type of MRD after chemotherapy when compared to the sub-type of MRD pre-chemotherapy. In patients converting from negative pre-chemotherapy to positive after chemotherapy for the presence of CTCs and/or micro-metastasis, a simplistic explication would be due to sampling error and that the limits of the methodology did not detect all of the patients with CTCs and/or micro-metastasis pre-chemotherapy. However, another explication is that a sub-group of tumour cells are relatively resistant to chemotherapy, a possible reason is the low proliferative index of these cells [5, 25]. In addition, the phenotypic characteristics of the tumour cells will determine the response to chemotherapy. CTCs positive for CD133 [26], CD26 [27] or increased thymidylate synthase expression [28] had poorer responses to chemotherapy and may continue to proliferate during treatment. There is little published evidence on the impact of pre and post-chemotherapy MRD in non-metastatic colon cancer. Romiti et al [29] reported using an EpCAM based system that in Stage III patients pre-chemotherapy CTC counts were not associated with prognosis, whereas post-chemotherapy CTC counts were. Post-operative CTCs but not pre-operative CTCs are associated with a worse prognosis [30] as are CTCs post FOLFOX for Stage III cancer [31].

In our reported study, the three sub-types of MRD were associated with differing clinical outcomes. Patients MRD negative had an excellent 5 -year disease-free survival of $87 \%$ with a mean time to failure of 4.6 years. Those patients positive for CTCs had a much worse prognosis with a 5 -year disease-free survival of only $6 \%$ and a mean time to progression of 1.5 years. Thus patients negative for CTCs but positive for micro-metastasis had a similar outcome to MRD negative patients for the first 18 months post-chemotherapy. Thereafter, there was an increasing relapse rate, with a disease-free progression after 5 years of $62 \%$ and a mean time to relapse of 4.0 years. The results suggest that these patients are at risk of late relapse. 
Our results suggest that there are at least three sub-types of MRD, each with a differing pattern of clinical relapse and time to failure. Patients MRD negative after chemotherapy have an excellent prognosis, while those who are CTC positive have a poor prognosis and may benefit from additional therapies. Importantly, there is a group of patients who are CTC negative but with evidence of MRD who are at risk of late relapse. Interesting in patients with non-metastatic breast [32] and non-metastatic prostate cancer [23], similar patterns of relapse have been reported.

We recognise that the small number of patients limits the conclusions; however, the results suggest that the sub-classification of MRD gives meaningful clinical results and warrants larger multi-centre studies.

\section{Conclusions}

The results of the study suggest that the sub-type of MRD detected after chemotherapy may have clinical meaningful utility in the risk classification of patients for relapse. MRD status pre-chemotherapy does not predict the outcome of treatment, with there being a heterogeneous response. The results warrant further larger scale studies.

\section{Acknowledgments}

The authors would like to thank Mrs Ana Maria Palazuelos for help in the writing of this manuscript.

\section{Funding}

The research was funded by a Hospital de Carabineros de Chile Research Grant.

\section{Conflict of interest}

Dr Murray has received consultancy fees from ViatarCTC Solutions, Boston, USA.

\section{References}

1. NCCN guidelines 2008 [http://www.nccn.org/professionals/physician_gls/pdf/colon.pdf]

2. Brenner H, Kloor M, and Pox CP (2014) Colorectal cancer Lancet 383 1490-1502 https://doi.org/10.1016/S0140-6736(13)61649-9

3. Rahbari NN, Aigner M, Thorlund K, et al (2010) Meta-analysis shows that detection of circulating tumor cells indicates poor prognosis in patients with colorectal cancer Gastroenterol 138 1714-1726 https://doi.org/10.1053/j.gastro.2010.01.008

4. Viehl CT, Weixler B, Guller U, et al (2017) Presence of bone marrow micro-metastasis in stage I-III colon cancer patients is associated with worse disease free and overall survival Cancer Med 6 918-927 https://doi.org/10.1002/cam4.1056 PMID: 28401701 PMCID: 5430093

5. Kasimir-Bauer S, Mayer S, Bojko P, et al (2001) Survival of tumor cells in stem cell preparations and bone marrow of patients with high risk or metastatic breast cancer receiving dose-intensive or high dose chemotherapy Clin Cancer Res 7 1582-1528 PMID: 11410494

6. Edge SB, Byrd DR, Compton CC, et al (2010) AJCC Cancer Staging Manual 7th edn (New York, NY: Springer Verlag)

7. Borgen E, Naume B, Nesland JM, et al (1999) Standardization of the immunocytochemical detection of cancer cells in bone marrow and blood. Establishment of objective criteria for the evaluation of immunostained cells Cytotherapy 5 377-388 https://doi. org/10.1080/0032472031000141283 
8. Murray NP, Reyes E, Tapia P, et al (2012) Redefining micro-metastasis in prostate cancer-a comparison of circulating prostate cells, bone marrow disseminated tumor cells and micro-metastasis: implications in determining local or systemic treatment for biochemical failure after radical prostatectomy Int J Mol Med 30 896-904 https://doi.org/10.3892/ijmm.2012.1071 PMID: 22825050

9. Rosner B (2010) Fundamentals of Biostatistics 7th edn (Boston, MA: Cengaje Learning) $859 \mathrm{p}$

10. Cleves M, Gutierrez R, Gould W, et al (2010) An Introduction to Survival Analysis Using Stata 3rd edn (Texas: Stata Press) 412 p

11. Royston P, Parmar MK (2013) Restricted mean survival time: an alternative to the hazard ration for the design and analysis of randomized trials with a time to event outcome BMC Med Res Methodol 13152 https://doi.org/10.1186/1471-2288-13-152

12. A'Hern RP (2016) Restricted mean survival time: an obligatory end point for time to event analysis in cancer trials? J Clin Oncol 34 3474-3476 https://doi.org/10.1200/JCO.2016.67.8045

13. Royston P, Lambert PC (2011) Flexible Parametric Survival Analysis Using State: Beyond the Cox Model (Texas: Stata Press) 347p.

14. Mikolajczyk SD, Miller LS, Tsinberg P, et al (2011) Detection of EpCAM negative and cytokeratin-negative circulating tumor cells in peripheral blood J Oncol https://doi.org/10.1155/2011/252361

15. Pantel K, Deneve E, Nocca D, et al (2012) Circulating epithelial cells in patients with benign colon diseases Clin Chem 58 936-940 https://doi.org/10.1373/clinchem.2011.175570

16. Marrinucci D, Bethel K, Kiloatkar A, et al (2012) Fluid biopsy in patients with metastatic prostate, pancreatic and breast cancers Phys Biol 9(1) https://doi.org/10.1088/1478-3975/9/1/016003

17. Calleja L, Chalopin A, Ory B, et al (2016) Circulating tumor cells: a review of non-EpCAM based approaches for cell enrichment and isolation Clin Chem 62 571-581 https://doi.org/10.1373/clinchem.2015.249706

18. Diekmann L. Beelen DW, Quabeck K, et al Presence of re-appearance of BCR-ABL positive cells years after allogeneic bone marrow transplantation for chronic phase chronic myelogenous leukemia in patients in haematological remission Acta Haematol 92 169-175

19. Arpinati M, Tolomelli G, Bochicchio MT, et al (2013) Molecular monitoring of BCR-ABL transcripts after allogeneic stem cell transplantation for chronic myeloid leukemia Biol Blood Marrow Transplant 19 735-740 https://doi.org/10.1016/j.bbmt.2013.01.007 PMID: 23333776

20. Sun Q, Liu Y, Liu B, et al (2018) Use of liquid biopsy in monitoring colorectal cancer progression shows strong clinical correlation Am J Med Sci 355 220-227 https://doi.org/10.1016/j.amjms.2017.09.009 PMID: 29549923

21. Gasch C, Bauernhofer T, Pichler M, et al (2013) Heterogeneity of epidermal growth factor receptor status and mutations of KRAS/PIK3CA in circulating tumor cells of patients with colorectal cancer Clin Chem 59 252-260 https://doi.org/10.1373/clinchem.2012.188557.

22. Kalikaki A, Politaki H, Souglakos J, et al (2014) KRAS genotype changes of circulating tumor cells during treatment of patients with metastatic colorectal cancer PLoS One 9(8) https://doi.org/10.1371/journal.pone.0104902

23. Murray NP, Aedo S, Fuentealba C, et al (2018) Minimal residual disease in patients post radical prostatectomy for prostate cancer: theoretical considerations, clinical implications and treatment outcome Asian Pac J Cancer Prev 19 229-236 PMID: 29374406 PMCID: 5844623

24. Takeyama H, Shimada T, Kinoshita S, et al (2017) Usefulness of CTC and DTC-BM detection for adjuvant therapy effects and prognosis prediction in early breast carcinoma: results of 8-11 years of follow-up evalution An Surg Oncol 24 1227-1233 https://doi.org/10.1245/ s10434-016-5714-1

25. Braun S, Kentenich C, Janni W, et al (2000) Lack of effect of adjuvant chemotherapy on the elimination of single dormant tumor cells in bone marrow of high risk breast cancer patients J Clin Oncol 18 80-86 https://doi.org/10.1200/JCO.2000.18.1.80 PMID: 10623696

26. linuma H, Watanabe T, Mimori K, et al (2011) Clinical significance of circulating tumor cells, including cancer stem-like cells, in peripheral blood for recurrence and prognosis in patients with Dukes' stage B and C colorectal cancer J Clin Oncol 29 1547-1555 https://doi. org/10.1200/JCO.2010.30.5151 PMID: 21422427 
27. Lieto E, Galizia G, Orditura M, et al (2015) CD26 positive/CD326-negative circulating cancer cells as prognostic markers for colorectal cancer recurrence Oncol Lett 9 542-550 https://doi.org/10.3892/ol.2014.2749 PMID: 25624884 PMCID: 4301532

28. Abdallah EA, Fanelli MF, Buim ME, et al (2015) Thymidylate synthase expression in circulating tumor cells: a new tool to predict 5-fluorouracil resistance in metastatic colorectal cancer patients Int J Cancer 137 1397-1405 https://doi.org/10.1002/ijc.29495 PMID: 25721610

29. Romiti A, Raffa S, Di Rocco R, et al (2014) Circulating tumor cells count predicts survival in colorectal cancer patients J Gastrointestin Liver Dis 23 279-284 PMID: 25267956

30. Yang C, Shi D, Wang S, et al (2018) Prognostic value of pre- and post-operative circulating tumor cells detection in colo-rectal cancer patients treated with curative resection: a prospective cohort study based on ISET device Cancer Manag Res $104135-4144$ https://doi.org/10.2147/CMAR.S176575 PMCID: 6177518

31. Lu CY, Tsai HL, Uen YH, et al (2013) Circulating tumor cells as a surrogate marker for determining clinical outcome to mFOLFOX chemotherapy in patients with stage III colon cancer Brit J Cancer 108 791-797 https://doi.org/10.1038/bjc.2012.595 PMID: 23422758 PMCID: 3590657

32. Takeyama H, Shimada T, Kinoshita S, et al (2017) Usefulness of CTC and DTC-BM detection after adjuvant therapy effects and prognosis prediction in early breast carcinoma: results of 8-11 years of follow-up evaluation Ann Surg Oncol 24 1227-1223 https://doi. org/10.1245/s10434-016-5714-1 